\title{
Factors Affecting Income Inequity Among Healthcare Workers in Iran: A Commentary
}

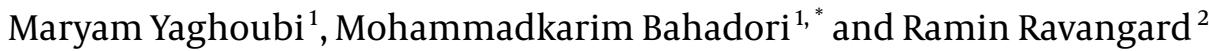 \\ ${ }^{1}$ Health Management Research Center, Baqiyatallah University of Medical Sciences, Tehran, Iran \\ ${ }^{2}$ Health Human Resources Research Center, School of Management and Medical Information Sciences, Shiraz University of Medical Sciences, Shiraz, Iran \\ "Corresponding author: Health Management Research Center, Baqiyatallah University of Medical Sciences, Tehran, Iran. Email: bahadorihealth@gmail.com \\ Received 2018 February 07; Revised 2018 October 20; Accepted 2018 October 21.
}

Keywords: Income, Inequity, Healthcare, Iran

\section{Dear Editor,}

In Iran, unlike developed countries, there is no clarity about the income of physicians, especially specialists. In addition to the income gap among the specialists, there is a huge difference in income between specialists and other health professional groups providing health services (1). It is very difficult and sometimes impossible to calculate the actual income of physicians in Iran due to the lack of information, financial, and regulatory systems and therefore, there are many ways to avoid this clarity; this is because in addition to the salaries paid to them in governmental centers, they usually visit a large number of patients in their offices and earn money by providing services such as the EKGs, EEGs, ultrasonographies, etc. which, unfortunately, there is not any clear report of such earnings $(2,3)$.

The lack of transparency, irrationality, and huge disparities existed between the incomes of specialists and other health service providers have provided opportunities for making claims by other medical personnel, especially nurses and physicians. The feeling of indifference to and alienation from the system and the forced extra work for the health care team is such that it seems they are working for a particular group, and this feeling leads to their physical and mental deterioration, which is more visible in Iran than in the other countries (4).

The question that arises is why this huge difference in incomes was created in Iran. There are seven reasons for the high-income gap among health workers in Iran:

1-The fee for service payment method:

This payment method increases the possibility of inducing demand and providing more services by the health care providers $(5,6)$. As long as this payment method is not corrected, inequities will be prevailed not only in the payment system, but also in all behavioral and administrative levels.

2-The existence of a conflict of interests in setting the medical tariffs:

In Iran, the method of setting tariffs is such that the Ministry of Health and Medical Education (MOHME) and the Islamic Republic of Iran Medical Council (IRIMC) offer their suggestions to the Supreme Council of Health Insurance, and this council submits approvals. Then, after the approval of the Planning and Budget Organization (PBO), the Government Cabinet approves the tariffs. This process shows that the physicians themselves set tariffs on their services.

3- Weaknesses of rationing system such as the referral system:

This factor has prevented the implementation of system rationing and leveling. Nongovernmental specialists have more incentives to increase their income by encouraging their patients to use unnecessary health care services and medications than those who work at government hospitals and clinics with a fixed income.

4- The lack of a progressive rate of income tax:

In many countries, workers whose revenues are higher than ten times the average income of the community must pay very high tax rates of 65 to 80 percent. Therefore, such workers in these countries have no incentive to work more than usual and in turn, pay heavy taxes. However, in Iran, due to the weaknesses of the tax and information systems, tax payments have led to the class gaps.

5- The implementation of the health transformation plan (HTP):

One of the goals of the HTP in Iran was to increase the medical tariffs. The main justifications for increasing medical tariffs in the HTP were increasing the quality of medical services, increasing the presence of physicians in 
the public sector, compensating for the lack of physicians in deprived areas, decreasing informal payments received from patients, and reducing the patients' contributions and out-of-pocket payments. Accordingly, in November 2014, the implementation of the third step of the HTP began which its main aim was the increase of 2.5 times in the salary of specialists. Despite this unprecedented increase, at the beginning of 2015 and only less than six months after the start of the third step, medical tariffs rose again by about 10\% (7). One of the other characteristics of the HTP is its extremely high use of financial incentives for changing the physicians' behavior (8).

6- The lack of specialists in some specialized fields that can reduce competition in the related specialists' services market:

Another important factor is the number and distribution of specialists so that in some specialized fields, there are not enough specialists. In other words, the inappropriate distribution of specialists is such that in some parts of the country, the number of specialists is more than the standards and in some other parts, there are not enough specialists in proportion to the number of people (8).

7- Paying attention to cure and treatment rather than prevention:

In most hospitals and medical centers of Iran, the health services are based on cure and treatment and the concept of health promotion and its significant role in the community health have not been institutionalized (9). This leads to great increases in the healthcare services provided by specialists and excessive surgeries.

Finally, it should be noted that specialists' incomes are part of the overall health budget of the country. Therefore, if their income is fundamentally unclear and there are inequities in payments between specialists and other health professional groups, this question will arise how to look for equity in health?

\section{References}

1. Homaie Rad E, Bayazidi Y, Delavari S, Rezaei S. Gender gap and inequality in health professionals' income in Iran. Med J Bakirkoy. 2016:74-9. doi: 10.5350/btdmjb201612204.

2. Jena $A B$, Olenski AR, Blumenthal DM. Sex differences in physician salary in US public medical schools.JAMAIntern Med.2016;176(9):1294304. doi: 10.1001/jamainternmed.2016.3284. [PubMed: 27400435]. [PubMed Central: PMC5558151].

3. Yi-jiong RE, Qing-ying JI. Analysis of salary distribution system in public hospitals. J Shanghai Jiaotong Univ. 2013;6(4).

4. Yaghoubi M, Afshar M, Javadi M. A study of relationship between the organizational justice and organizational citizenship behavior among nurses in selected hospitals of Isfahan University of Medical Sciences. Iran J Nurs Midwifery Res. 2012;17(6):456-60. [PubMed: 23922589]. [PubMed Central: PMC3733293].

5. Gosden T, Forland F, Kristiansen IS, Sutton M, Leese B, Giuffrida A, et al. Impact of payment method on behaviour of primary care physicians: A systematic review. J Health Serv Res Policy. 2001;6(1):44-55. doi 10.1258/1355819011927198. [PubMed: 11219360].

6. Neumann M, Bensing J, Wirtz M, Wubker A, Scheffer C, Tauschel $D$, et al. The impact of financial incentives on physician empathy: A study from the perspective of patients with private and statutory health insurance. Patient Educ Couns. 2011;84(2):208-16. doi: 10.1016/j.pec.2010.07.012. [PubMed: 20708897].

7. Bahadori M, Ravangard R, Alimohammadzadeh K, Hosseini SM. Plan and road map for health reform in Iran. BMJ. 2015;351:h4407. doi 10.1136/bmj.h4407. [PubMed: 26285708].

8. Bayati M, Rashidian A. Target income and its determinants for general physicians: An instrumental variables approach. Int J Healthcare Manag. 2017;11(3):260-8. doi: 10.1080/20479700.2017.1389477.

9. Yaghoubi M, Javadi M, Bahadori M, Ravangard R. Health promoting hospitals model in Iran. Iran J Public Health. 2016;45(3):362-9. [PubMed: 27141499]. [PubMed Central: PMC4851751]. 